\title{
Ingenio verbal y poética de la sinrazón ante la crisis bursátil: Joseph Penso y su Confusión de confusiones
}

\section{Verbal Wit and Poetic of Unreason in the face to the Stock Exchange Crisis: Joseph Penso and his Confusion of Confusions}

\section{Fernando J. Pancorbo}

Universität Basel

SUIZA

fernandojose.pancorbomurillo@unibas.ch

[Hipogrifo, (issn: 2328-1308), 7.1, 2019, pp. 633-651]

Recibido: 28-09-2018 / Aceptado: 04-12-2018

DOI: http://dx.doi.org/10.13035/H.2019.07.01.47

Resumen. La obra Confusión de confusiones, escrita por el sefardí Joseph Penso de Vega (Ámsterdam, 1688), está considerada como el primer tratado de la Bolsa de Acciones de Europa. Desde el punto de vista de la Historia de la Economía, sin duda, sigue planteando enigmas y cautivando el interés de sus estudiosos. El problema es que desde la perspectiva literaria e historiográfica no ha recibido aún un estudio en profundidad, hecho que desluce y terminar por restar su verdadero mérito a este texto, el cual - dicho sea de paso- ha permanecido siglos condenado en las estanterías de "volúmenes raros". En este artículo ofrezco un estudio en el que trato la verdadera génesis de Confusión de confusiones desde el interés histórico y literario.

Palabras clave. Sefardíes; diálogos; Ámsterdam; Bolsa de Valores; crisis.

Abstract. Confusion of confusions wrote by the Sephardic writer Joseph Penso (Amsterdam, 1688), is considered as the first treatise about the Stock Exchange in Europe. From the perspective of Economic History, the work continues presenting enigmas and catching the interest of the scholars. The problem is that there is 
not too much depth study from Historiography and Literature. This fact condemns Penso's books to be forgotten in the "rare volumes" sections. In this article, I offer a study studying the real genesis of Confusion of Confusions from the Historic and Literary interest.

Keywords. Sephardim; Dialogues; Amsterdam; Stock Exchange; Crisis.

En 1688 se publica en las prensas de David Castro Tartás Confusión de confusiones, título por el que se recuerda a Joseph Penso de Vega -el resto de su producción no había sido del interés de los estudiosos hasta hace relativamente poco-, acaso el autor de prosa más célebre de la comunidad sefardí de Ámsterdam durante el siglo XVII . Su temática, centrada en la materia económica y a la advertencia los peligros que entraña el mundo de la Bolsa de Acciones, han dado lugar a un buen número de ensayos sobre Derecho Mercantil, Historia de la Economía y estudios que satisficiesen la curiosidad de los bibliófilos. No obstante, la obra apenas ha recibido aún un tratamiento literario en profundidad que desenmarañe todas las complejidades que plantea, hecho que se puede observar en la mayoría de las ediciones modernas del texto de Penso, salvo contadas excepciones².

A pesar de lo atractivo que puede resultar estudiar el contexto histórico en el que surgió Confusión de confusiones, no considero que sea necesario ofrecer aquí una revisión o un estado de la cuestión sobre la visión de Ámsterdam como eje financiero y uno de los mayores puntos de distribución de mercancías de Europa del siglo XVII, ni de su hegemonía mercantil y su monopolio en las principales zOnas costeras de Asia debido el papel desempeñado por la Compañía de las Indias Occidentales (Vereenigde Oost-indische Compagnie) ${ }^{3}$. De hecho, cabe pensar que este enfoque, el más recurrente, sea una posible vía de esquivar los problemas que presenta el hecho de no encontrar unos antecedentes literarios claros o no entender que esta obra, destinada durante años a llevar el apellido de «raro» ${ }^{4}$, se trata de una miscelánea compleja que aglutina varias tradiciones.

1. Sobre la vida y obra de Joseph Penso ofrezco mi tesis doctoral (Pancorbo, 2018), que se encuentra en la Universität Bibliothek de Basel y se puede consultar bajo petición.

2. Con estas excepciones me refiero concretamente a la edición de Confusión de confusiones realizada por M. F. J. Smith, 1939; y la más reciente, la de Pablo Gasós y Margarita González, 2015. Estas son, a mi juicio, las que mayor información biográfica y literaria han aportado a la obra de Joseph Penso.

3. No es mi intención hacer aquí una revisión bibliográfica de todos los estudios que se han hecho sobre la VOC, pero considero útil traer algunos estudios que, desde mi punto de vista, son de obligada referencia como el de Gosselink, 2015, en el que el autor ofrece un estudio detallado sobre la creación de la Compañía de las Indias Occidentales; las dos obras que dedicó al tema Jonathan I. Israel, 1989. Como referencia documental para la historia de la compañía, recomiendo el trabajo de Landwehr, 1991. No deja ser tampoco una referencia en estos estudios, sobre todo para tener una idea clara acerca del impacto que tuvo a nivel político y social el desarrollo de la VOC, el trabajo de Winius y Vink, 1991. Para tener una idea general más cercana al contexto de Confusión de confusiones, remito a Chaeudhuri e Israel, 1991. Por último, creo interesante mencionar el trabajo de Gaastra, 2003.

4. Es frecuente ver el título de Confusión de confusiones incluido en los catálogos como un volumen raro, sobre todo a partir de comienzos del siglo XIX. Una de las primeras veces que se encuentra en este 
Debió de ser a finales de 1687 cuando Penso terminó este volumen divido en «cuatro diálogos curiosos entre un filósofo agudo, un mercader discreto y un accionista erudito», texto que se ha entendido a caballo entre un tratado económico, el primero para ser exacto, y las memorias de un corredor de bolsa, aunque se le ha adscrito prácticamente a tantos géneros como veces se ha estudiado ${ }^{5}$. Esta inexistencia de un consenso entre los estudiosos repercute de manera directa a la hora de intentar saber cuáles fueron realmente los motivos que le llevaron al autor sefardí a escribir esta obra y cuáles son los marcos teóricos sobre los que se construye.

Es cierto que Joseph Penso, mercader y comerciante antes que escritor ${ }^{6}$, da muestras evidentes de haber estado atravesando una grave crisis económica personal. Basta, como muestra, la denuncia pública que hizo Miguel de Barrios para hacer saber que Joseph Penso incumplió su palabra al no querer repartir los 500 cruzados que les envió el rey Pedro II de Portugal por haber escrito los dos juntos - Penso la parte en prosa y Barrios los pasajes en verso- un encomio nupcial con motivo de su enlace real con María Sophia de Niewburg ${ }^{7}$. El escritor sefardí fue

tipo de catálogos es en un trabajo realizado por un bibliotecario español afincado en Londres: Salvá, 1826, p. 213. Años más tarde, se vuelve a encontrar en un inventario una entrada correspondiente a Confusión de confusiones, en un Catalogue raisonné de la Bibliothèque d'un Chateau de Lorraine, 1862, vol. I, p. 79. En España tarda un poco en registrarse la obra de Penso, pero sigue presentando un estigma de extrañeza, tal y como se puede ver en el apartado de «Obras raras y antiguas» que se encuentra en el Boletín de La Librería, 1874, p. 156.

5. Véase que, por ejemplo, José Antonio Torrente Fortuño, en un capítulo titulado de manera curiosa "Memorias del bolsista José de la Vega», intenta arrojar algo de luz con respecto a este tema cuando dice: «Confusión de confusiones no es un tratado de Bolsa, no es obra de un economista, ni de un economista, ni de un historiador, ni de un mercantilista. Falta temática para ser un tratado, falta sistematización, valora de modo muy diverso los componentes de la institución bursátil, carece del menor estudio sobre fuentes, no tiene ningún apartado jurídico» (Torrente Fortuño, 1980, pp. 58-59).

6. Existe una idea general de que Penso se ganaba la vida como escritor - quizás por querer equipararlo de manera forzada con los tópicos literarios del Siglo de Oro español-, pero realmente sus principales labores y sus fuentes de ingresos procedían de sus tratos comerciales, hecho que se explica por los cerca de los trece años que estuvo viviendo con su hermano, su mujer y sus hijos en Livorno, velando por las redes de negocios que tenía allí establecidas su padre. Para poder ver parte de la documentación relacionada con la vida de Penso en el ámbito de la comunidad judía de Livorno, es necesaria la consulta de Renzo Toaff, 1990 (el resto se encuentra ofrecido en mi tesis doctoral, anteriormente citada). En el plano cultural y en relación a la conformación de la diáspora livornesa, así como la explicación de cómo esta ciudad toscana se convirtió en uno de los principales enclaves mercantiles y comerciales del Mediterráneo, son de obligada referencia los trabajos de Trivellato, 2009, y el de Bregoli, 2014.

7. Este episodio fue muy sonado entre los sefardíes amstelodamos ya que, incluso, Miguel de Barrios realizó una denuncia declarando que: «Don Miguel de Barrios y don Joseph Penso de la Vega hicimos y dedicamos a su Majestad lusitana el panegírico regio de su feliz casamiento, con acuerdo de que partiéramos el premio. Enviolo su Majestad, de quinientos cruzados por vía de su Excelencia el Agente Gerónimo Núñez de Acosta, que se lo entregó al propuesto Vega; el cual no me dio los 250 cruzados que me tocaban, por quedarse con todos los 500 negando que los mandó el Rey por este elogio», en Dios con nosotros, Ámsterdam, 1688. Para hacerse una idea aproximada de la cuantía de esta recompensa, 500 cruzados portugueses equivaldrían a unos 1500 florines, información que ofrezco a partir de las tablas de equivalencias que ofrece Óscar Fernández Ruíz en su tesis doctoral presentada en la Universidad de Valladolid en 2012, p. 3. Se tendrá aún una idea más clara del valor del premio al saber que el salario anual de un rabino de la talla de Moseh Raphael de Aguilar era de cuatrocientos florines al año, tal 
víctima de lo que se ha reconocido como el primer «crack» que hubo en Europa, producto de la especulación comercial. De hecho, Penso, entre los bosquejos autobiográficos que ofrece a lo largo de su obra puestos en boca de sus personajes, da las cifras exactas que hicieron estallar este desastre:

ACCIONISTA Creo que estáis de gorja para recrearos con el despeño de un triste y, porque no sea sin alguna pensión el pasatiempo, sabed que las acciones del Oost se largan por 370 y las del West por 75.

FILósofo ¡Válgame Dios, que día de juicio tan "horrífero"! Téngame Dios por su misericordia el juicio. Aún vos os libráis con los 15 por ciento del opsie, que son 450 florines, del susto; mas yo pierdo ya de 552 2/3 a 370, que son florines 5480, en la partida y va caminando el peligro sin saber dónde será el remate de la furia. ¡Ay, tal violencia! ¡Ay, tal velocidad! ¡Ay, tal rigor! No sé lo que hice, ni sé lo que hago, ni sé lo que he de hacer. [...] ¿Qué podía esperar un filósofo entre accionistas si no ser como oveja entre lobos, liebre entre galgos? Y aunque Escalígero asegura como portento que hubo un lobo manso entre ovejas y un galgo apacible entre liebres, por eso lo nota como maravilla y lo observa como portento.

Accionista $\quad[. .$.$] Treinta por ciento bajaron las acciones el primer$ día de la catástrofe, y otros treinta el segundo; con que será la primera aplicación la del premio del enigma que fue treinta y treinta. ¿Quién es aquí el Sansón que significa el sol? Los liefhebberen que siempre desean el lucimiento de la patria. ¿Quiénes son los filisteos cuyo nombre representa al que se revuelva en el polvo? Los contraminores que muestran aspirar a que todo se reduzca a polvo, a pavesas, a cenizas. ¿Quién simboliza el enigma? La Fortuna, que por su inconstancia la pintaron todos con semblante de mujer. Celebren pues los contraminores su dicha, ya que tuvieron propicia a la Fortuna que les explicó el enigma; con que, adivinando la proposición, lograron el premio. ¿Y qué ganaron? Sábanas, cortinas y unas galas que llamándoles el Sacro Texto Halisot, deducido del verbo Halas, prueba el erudito Pómez significar el que se muda, el que falta a su obligación, y el que se arruina. Una sábana que se traía al sacerdote

y como se puede ver en el «Termo das causas que ouvo para fazer hum medrás novo e se admitir o Rubí nelle a Moseh Raphael de Aguilar», documento que se encuentra en el Gemeentearchief Amsterdam (GAA / Pa 334, núm. 9, fol. 459). Es decir, Penso se adueñó de una cantidad proporcional al sueldo de más de tres años de un rabino -la cifra de Moseh Raphael de Aguilar no es en sí demasiado orientativa porque fue muy cotizado-, hecho que se encuentra reflejado en mayor detalle en Bodian, 1997, p. 110. 
quería Dios que fuese la piedra de toque del honor; con que lo primero que ganaron fue la sábana en que se amortajó el honor de tantos. Ganaron más las cortinas del funesto teatro en que se representó esta tragedia, quedándose muchos al paño por no poder lucir con el pa- pel que les tocaba. Ganaron, finalmente, la ruina de los más poderosos, la mudanza de los más firmes y faltar a su obligación los más atentos. ¿Pero que harían los pobres liefhebberen viéndose vendidos de la fortuna, sin tener como Sansón con que poder pagar lo que perdían? ¿Ir a robar a unos para pagar a otros? No mejor hicieron; no dieron lo que no tenían, mas no dieron lo que robaban, pues menos criminal no pagar lo que se debe que ir a robar lo que se paga; porque el que no paga lo que no puede solo parece que roba lo que no da más el que roba para pagar, se ve evidentemente que roba.

Todo apunta a que la hipótesis de que el génesis de esta obra fuesen sus infortunios en los tratos bursátiles, pero tampoco es un hecho que se pueda dar entender como algo fiable ${ }^{8}$. En el caso que relata el autor en Confusión de confusiones, lo que sucedió es que la VOC esperaba un cargamento de considerable importancia y eso hizo aumentar el precio de las acciones a unas cotizaciones sin precedentes, algo que no se repetía desde la famosa «Tulipomanía»?. Se creó una burbuja cuya consecuencia fue que la especulación llevase su compromiso al máximo ${ }^{10}$. La clave del problema fue que, desde el comienzo de la campaña, empezaron a llegar malas noticias, ya que hubo embarcaciones que sufrieron graves averías y tuvieron que retornar desde el Cabo de Buena Esperanza a Batavia (la actual Yakarta), que era la principal capital financiera de Holanda en Asia ${ }^{11}$. No obstante, el resto de las naves cumplieron su misión. El resultado de esta cadena de relativos infortunios es que el precio de las mercancías se devaluó de manera considerable. Es decir, se contaba con un contravalor de 50 toneladas de oro y, finalmente, el beneficio fue de 35. La venta de los productos no fue, en sí, un mal negocio, pero la especulación sobrepasó todos los límites ${ }^{12}$. De hecho, si se atienden a las estadísticas mercantiles de

8. Sería de esperar haber encontrado algún indicio de esta información en los Libros de la Nação o en relaciones de fintas para poder constatar si lo que se presenta en Confusión de confusiones es realidad o ficción, pero no hay ningún dato al respecto.

9. Tomo la referencia de Mackay, 1852, pp. 85-92

10. Como antes adelantaba, son muchos los investigadores que se han ocupado de Confusión de confusiones desde un punto de vista histórico-económico, pero me limitaré en este punto a indicar los trabajos sobre los que me he apoyado, además de los estudios introductorios de las ediciones que se conservan, que creo más relevantes. Uno de las primeras obras que sigue siendo de referencia es la de Cardoso, 2002. Resulta de gran interés en este aspecto el reciente trabajo de Dumez, 2003. Y, por último, la tesis doctoral de Perramón Ayza, 2011 (consultable en línea).

11. Las malas infraestructuras y las deficiencias logísticas de buena parte de las naves de la VOC se pueden encontrar explicadas en Duivenvoorde, 2015, pp. 1-3.

12. Esto se puede ver ampliamente estudiado en Kostolany, 1962, pp. 97-98. 
1687-1688, no se deberían considerar como dos de los peores años, ya que la caída de los beneficios no fue tan acusada ${ }^{13}$. Realmente, Confusión de confusiones, en este sentido, es el reflejo de un escarmiento que se llevó Penso como accionista y su desgracia a partir de una operación financiera fraudulenta.

Con bastante seguridad, y teniendo en cuenta la crisis que estaba atravesando, el autor tuviese que pensar en hacer de la literatura su principal fuente de ingresos, casi como una única carta que jugar. Son varios los detalles que hacen llegar a la conclusión de que Confusión de confusiones fue escrita con una intención comercial y no como un producto de su mera vocación literaria, al contrario de como ocurrió con el resto de sus obras. Es la primera vez que Penso reúne en un solo texto todas las fuentes clásicas, las religiosas, las españolas y las italianas que conocía, aunque esto se pudiese entender como una exagerada gala de su erudición y de la novedad de la materia que trata ${ }^{14}$. Por otro lado, es la primera vez que Penso se dirige de manera abierta al máximo público posible ya que camufla su identidad religiosa -al menos en la portada ${ }^{15}$ - , el nombre del impresor y declara «haber determinado traducir estos discursos al francés para que sea más general la noticia de un juego sobre el que nadie hasta hoy ha escrito» ${ }^{16}$. No obstante, las aspiraciones editoriales de Penso no subsumieron o eliminaron el compromiso cultural con sus correligionarios. De hecho, nadie mejor que los judíos de la comunidad amstelodama iban a entender el contenido y las advertencias que ofrece el autor en su obra, máxime si se tiene en cuenta que ellos, concretamente los sefardíes, tenían una notable presencia - al menos en ese momento- en los círculos bursátiles ${ }^{17}$. Por

13. Estas gráficas se pueden consultar en Winius y Vink, 1991, pp. 157-184.

14. No significa esto que las fuentes que usaba fuesen cajones estancos, pero sí que es cierto que Joseph Penso recurría a ellas de manera muy concreta y, cada una de ellas, destinada a un determinado fin y a textos específicos en algunos de los casos.

15. Por lo general, hay varios indicios sistemáticos que evidencian el público al que va dirigido un libro escrito por algún sefardí de la comunidad judía amstelodama, como el uso del nombre en forma cristiana o hebrea, la falsificación del pie de imprenta, la eliminación del nombre del impresor, etc. Esto se encuentra estudiado en Boer, 1987, pp. 99-104; y, también de Boer, 1995, pp. 314-319.

16. Penso, Confusión de confusiones, ed. Smith, p. 67. Desgraciadamente, no existe ninguna traducción de época ni ninguna referencia que la mencionase tan siquiera en sus círculos más cercanos. Coincido plenamente con Harm den Boer y con Jonathan I. Israel cuando explican que: «At the close of this dialogue, Penso de la Vega, who himself belonged to a well-known Sephardi business family, urgues his readership -mainly but not necessarily exclusively Sephardi Jews - to invest in East and West India Company shares only in a sober, responsible manner and, as far as possible, to support the patria, the Dutch homeland, and the great colonial Companies, by preferring to buy rather tahn sell!», en Boer e Israel, 1991, pp. 439-462.

17. A comienzos del siglo XVII, el número de sefardíes que desarrollaban su actividad como brokers era, aproximadamente, de unos trescientos y estaban especializados en la comercialización de productos procedentes de Levante y de Sudamérica, especialmente de azúcar, como explica Israel, 1989, p. 74. Es de esperar que la tendencia de sefardíes que centraban sus intereses en este negocio fuese creciente, máxime tras haber recibido el título de ciudadanos de pleno derecho el 12 de julio de 1657, ya que esto cesaba las prohibiciones que limitaban los oficios que podían desempeñar los judíos en Ámsterdam, hecho que explica Torrente Fortuño, 1980, pp. 49-50. Este incremento llegó hasta tal punto que los judíos se hicieron prácticamente con el control de la Bolsa, siendo su actividad más representativa que la del resto de sectores locales e internacionales, como se puede ver en Israel, 2002, p. 11. 
consiguiente, a pesar de que su intención primera era la de querer llegar al mayor público posible, se puede entender que las advertencias ofrecidas en el texto van, fundamentalmente, dirigidas a los accionistas y corredores con los que compartía fe.

Partiendo de esta idea, toman pleno sentido las tres razones que ofrece Penso en su prólogo para justificar la escritura de Confusión de confusiones:

El primero, entretener el ocio con algún deleite que no desdore lo molesto. El segundo, describir (para quienes no lo ejercitan) un negocio que es el más real y útil que se conoce hoy en la Europa. Y el tercero, pintar con el pincel de la verdad las estratagemas con que lo tratan los tahúres que lo desdoran para que a unos sirva de delicia, a otros de advertencia y a muchos de escarmiento 18.

La obra más importante de Penso de Vega, por lo tanto, se debe entender como un texto dirigido a un gran público, en el que no hay razones ni evidencias notables a primera vista para acusar posibles prejuicios por parte de los lectores cristianos, a los que les correspondería, en su mayor parte, una lectura ociosa. En un ámbito más concreto, el texto se presenta como un compendio de lecciones magistrales, de cauciones y peligros sobre los problemas que entrañan estos tratos comerciales y económicos con los que, supuestamente, deberían estar familiarizados sus correligionarios y, tal vez, como un consuelo racional para aquellos que, como él, sufrieron estos estragos.

La opera magna de Joseph Penso plantea problemas desde el título, ya que da pie a numerosas interpretaciones, algunas de ellas un tanto forzadas debido a que se ha querido buscar una explicación de carácter religioso, económico o, incluso, mitológico ${ }^{19}$. No obstante, coincidiendo con la hipótesis que plantea Antonio Rey Hazas, Confusión de confusiones tiene una explicación meramente literaria y, más concretamente, si se atiende a las lecturas que, con seguridad, hizo de manera provechosa, como es el caso de Calderón de Barca ${ }^{20}$. El autor sefardí conoció bien algunas de las obras del clérigo español, ya que, de hecho, la primera obra que Pen-

18. Penso, Confusión de confusiones, ed. Smith, p. III.

19. Realmente, hay dos grandes líneas de interpretación bien definidas con respecto al posible origen del nombre de la obra. La primera, defendida por Hermann Kellenbenz - que retoma de la ya mencionada edición de M. F. J. Smith de 1939-, en la que dice que: «He called the dialogues Confusión de confusiones because there was no rational purpose in the activities which was not overlaid with an irrational one, no trick used by one person which others didi not pay back with the same coin, so that, in this Stock-Exchange Business, one moved in a world of darkness which nobody understood and no pen was able really to describe in all its intricacies», en Kellenbenz, 1957, p. XI. Otros establecen una equiparación de carácter religioso con respecto a la falsa fe que profesaron los adeptos al movimiento mesiánico de Sabbatai Tzevi, como se dice en Held, 2006, pp. 131-133. Obviamente, ofrezco una referencia superficial por cuestiones de espacio, pero las interpretaciones se extienden incluso a interpretaciones tomadas del pasaje bíblico de la construcción de la Torre de Babel (Génesis, 11, 1-9) al tener en cuenta el escenario cosmopolita y la mezcla de lenguas que se reunía en la plaza Dam.

20. Son varios los estudios que han intentado demostrar la presencia de la literatura del Siglo de Oro en la comunidad sefardí de Ámsterdam. Sin embargo, creo que son estudios de obligada referencia el de Boer, 1995; y el trabajo de Kaplan, 2016. 
so escribió con apenas 17 años, 'Asîrê ha-Tiqwâ (Prisioneros de la esperanza) ${ }^{21}$, no deja de ser una recreación o adaptación que hizo de Los encantos de la culpa por medio de una lectura intercalada de la recreación calderoniana que publicó hacia 1655 Miguel de Barrios bajo el título de Contra la verdad no hay fuerza22. Sin duda, entre las obras de Calderón que debió leer con avidez Penso, así como otros sefardíes, estaría La dama duende, donde el personaje de don Manuel dice: «Aquí / muere un engaño, y concibe / otro engaño. ¿Qué he de hacer? / Que soy en mis opiniones / confusión de confusiones» ${ }^{23}$; o el auto sacramental El divino cazador, género con el que Penso también estuvo muy familiarizado, en el que el alegórico "género humano» explica que:
Dudando y creyendo estoy
ser humano y ser divino,
que como generaciones
tan distintas represento,
y dentro de mí sustento
tantas tan varias naciones,
confusión de confusiones,
no sé qué crédito y fe
a tanta admiración dé
como ha introducido en mí
sola esa voz ${ }^{24}$

Estos fragmentos presentan ese carácter dudoso y prácticamente incomprensible que se encuentra también en el texto de Joseph Penso cuando quiere da a conocer ese «mapa de tinieblas en el que no puede haber juicio que las comprenda ni pluma que las descifre» ${ }^{25}$. Hay que advertir, además, que la intertextualidad con Calderón llega a estar tan presente que incluso se ven copiados ad pedem litterae los versos más conocidos del monólogo de Segismundo en La vida es sueño, como se puede ver en el siguiente fragmento:

$\begin{array}{ll}\text { Filósofo } & \text { ¡Ay, mísero de mí! } \\ \text { MERCADER } & \text { ¡Ay, infelice! } \\ \text { Accionista } & \begin{array}{l}\text { Que si pago muriendo cielos, ¿qué culpa cometí } \\ \text { naciendo? Nace el ave... }\end{array}\end{array}$

21. A día de hoy se conservan dos ejemplares: el de 1673, publicado en Ámsterdam, en la imprenta de Joseph Athias; el segundo, una edición tardía de 1770, impresa por Carlo Giorgi (Jahacob Raphael Milol), en Livorno, y que se encuentra en la Biblioteca e Archivio delle Tradizioni e del costume ebraici Benvuto e Alessandro Terracini, en Turín, con la signatura Ant. Ebr.-1085.

22. Hago referencia a la edición de Ámsterdam, impresa por David de Castro Tartás en 5425 (1655), que se encuentra en la Ets Haim con la signatura A EH 20 E62.

23. Calderón de la Barca, La dama duende, p. 1490.

24. Calderón de la Barca, El divino cazador, p. 30

25. Penso, Confusión de confusiones, ed. Smith, p. VI. 


$\begin{array}{ll}\text { MERCADER } & \text { ¿Qué es esto? ¿Tenéis algún demonio en el cuerpo? } \\ \text { ¿Estáis endiablado? } & \text { ¿Qué es esto? Es ir siguiendo la gran comedia de } \\ & \text { La vida es sueño que vos habéis empezado } 26 .\end{array}$

La lectura de estos fragmentos sirve para darse cuenta de que, en sí, el título marcará el inicio de un desfile de nombres de autores y obras españolas que se extienden a lo largo de todo Confusión de confusiones. Esta gala de ingenio y erudición le dan la oportunidad a Joseph Penso de, entre otras cosas, hacer definiciones de tipos de accionistas equiparándolos a determinados títulos de obras castellanas, tal y como advierte Antonio Rey:

1) El palacio confuso, que es de Antonio Mira de Amescua (1574-1640), y alude con toda claridad a «todo cónclave», a la Bolsa en pleno movimiento de sus acciones; 2) Sufrir por más querer, de Jerónimo de Villaizán (1604 -1633), título que establece parangones con los alcistas (liefhebberen); 3) mientras con los bajistas (contraminores) equipara La fiera, el rayo y la piedra, comedia mitológica de su admirado Pedro Calderón de la Barca, escrita en 1652; 4) Entre bobos anda el juego, de Francisco de Rojas Zorrilla (1607-1648), alude a los «neutrales», esto es, a los que no juegan ni al alza ni a la baja; 5) No hay vida como la honra, de Juan Pérez de Montalbán (1602-1638) se refiere los que sopesan todo sosegada y despaciosamente («los cuidadosos»); 6) Dicha y desdicha del nombre, de Pedro Calderón de la Barca (1600-1681), indica a los que invocan a Federique; 7) Ventura te dé Dios, hijo, de Tirso de Molina (1579-1648), se aplica a los ganadores; 8) se refiere a los perdedores con Oponerse a las estrellas, comedia de «tres ingenios», Juan de Matos Fragoso (1608-1689), Antonio Martínez de Meneses (1608-1661) y Agustín Moreto (1618-1669); 9) para los interlocutores del accionista en el diálogo se dice que es conveniente Abrir el ojo, pieza de Francisco de Rojas Zorrilla (1607-1648); y 10) el accionista se refiere a sí mismo con la expresión Darlo todo y no dar nada, que es obra de don Pedro Calderón de la Barca (1600-1681); 11) Lo que pasa en una noche, en fin, es comedia de Antonio Coello (1611-1652), y con este título se alude al paso de la tranquilidad a la inquietud que produce el engaño de un accionista ${ }^{27}$.

No faltan tampoco las referencias encomiásticas a quienes ya fueron sus principales modelos y fuentes de inspiración en obras anteriores, como Rumbos peligrosos (1683) ${ }^{28}$. En la dedicatoria de Confusión de confusiones «Al muy ilustre señor Duarte Nunes da Costa», dice que «no hubo filósofo que comparase la vida a la mar $y$, habiendo padecido la pobre barquilla de mi ingenio tantas tormentas en sus olas, no es mucho que quiera formar una paradoja de la zozobra», palabras

26. Penso, Confusión de confusiones, ed. Smith, p. 73.

27. Cito desde el estudio introductorio realizado por Antonio Rey Hazas «Confusión de confusiones considerada como literatura», en Penso, 2015, pp. 162-163.

28. Joseph Penso, Rumbos peligrosos por donde navega con título de novelas la zozobrante nave de la temeridad, temiendo los peligrosos escollos de la censura, Amberes [Ámsterdam], [Yahacob de Córdoba], 1683. 
que remiten de manera directa a los lopescos versos de Pobre barquilla la mía ${ }^{29}$. Lo mismo sucede con Miguel de Cervantes cuando Penso quiere exponer los peligros y la locura que encierra el mundo bursátil:

Los Quijotes defienden que lo inventó Sancho Panza, o por haber muchos en él que, en viéndose con dos ducados, luego creen que gobiernan dos ínsulas, o porque sirven como Sancho a un loco que combate con molinos de viento, o a la Fortuna que es más loca de lo que era el gracioso héroe de la Mancha, o por la Panza que hacen hinchándose los que lo tratan en conociendo que les sopla bien la dicha o que los alienta bien la Suerte ${ }^{30}$.

Incluso, Penso se permite el lujo de evidenciar ciertos ecos de Francisco de Quevedo, máximo representante del conceptismo Barroco español, así como del antisemitismo más exacerbado - hecho que no deja de ser curioso-, para recrear el famoso soneto de «Érase un hombre a una nariz pegado», cuando dice:

Procura encarecer uno ser persona de seguridad la que le dio la orden y pregona que es un hombre como una torre y que tiene tanto de nariz. [...] Que sea tanto de nariz, no lo contradigo, mas no he leído que salgan más que mocos de la nariz. [...] ¿Si será Ovidio Nasón el que nombran; sino es que auspician en su estado las metamorfosis de Ovidio? ¿Si será el hombre pegado a la nariz que pinta Quevedo este hombre? ${ }^{31}$.

Son suficientes algunos ejemplos para darse cuenta de que Penso enfoca el uso de estos modelos áureos con una doble intención: por un lado, para crear un reclamo de cara a aquellos lectores familiarizados con los autores y las obras propias del Barroco español; y, por otro lado, crear un sistema de equivalencias entre la temática de Confusión de confusiones y los referentes culturales de aquel público que no estuviese familiarizado con el mundo bursátil.

En este aspecto, se puede ver que el uso de las fuentes italianas está destinada a otros usos y, para ellos, es conveniente saber cuáles son sus textos de base y cuáles son citas mediadas tomadas de otras obras. En este sentido, es frecuente ver algunas referencias a autores de referencia del Renacimiento italiano, como es el caso del humanista Giulio Cesare Scaligero -conocido, entre otras cosas, por la invectiva que escribió contra Erasmo de Rotterdam (Oratio pro Cicerone contra Des. Erasmus, 1531), o por las observaciones que le hizo a Lorenzo Valla y a los humanistas precedentes en su De causis linguae latinae (1580)32-; o a Girolamo Cardano, a quien hace referencia por medio de su obra De subtitulate rerum

29. Los ecos lopescos en la obra de Penso son más que obvios: «Pobre barquilla mía, /entre peñascos rota, / sin velas desvelada, / y entre las olas sola: / ¿Adónde vas perdida? / ¿Adónde, di, te engolfas? / Que no hay deseos cuerdos /con esperanzas locas», en Lope de Vega, La Dorotea, p. 209.

30. Penso, Confusión de confusiones, ed. Smith, p. 19.

31. Penso, Confusión de confusiones, ed. Smith, pp. 112-113.

32. «¿Qué podía esperar un filósofo entre accionistas, si no ser como oveja entre lobos, liebre entre galgos? Y aunque Escaligero asegura como portento que hubo un lobo entre las ovejas y un galgo apacible entre liebres, por eso lo nota como maravilla y lo observa como portento» (Penso, Confusión de confusiones, ed. Smith, p. 139). 
$(1550)^{33}$. No obstante, estas citas no proceden directamente de su lectura sino de otros textos.

Junto a estos nombres, con los que Penso evidencia no estar familiarizado en ninguna de sus obras anteriores, aparecen otros a los que no solo menciona sino que recrea y emula en caso anteriores, como es el caso de Giovan Francesco Loredano, de quien conoce a la perfección sus Bizzarrie Academiche (1655) y de donde toma, por cierto, las sentencias de Scaligero y Cardano34; y de Emanuel Tesauro, tomando como claro apoyo su II cannocchiale aristotelico, ossia Idea dell'arguta et ingeniosa elocutione che serve a tutta l'Arte oratoria, lapidaria, et simbolica esaminata co. Principii del divino Aristotele (1654), y su Philosophia morale (1670). Este compendio de obras le sirven, además de para presentar un buen número de citas eruditas, para crear un puente con los principios poéticos y filosóficos de Aristóteles, sobre los que crea el marco teórico de sus diálogos.

Retomando algunas de las consideraciones generales, Confusión de confusiones es un texto segmentado en cuatro diálogos que cuentan con tres únicos interlocutores: un filósofo agudo, un mercader discreto, y un accionista erudito. Estos parlamentos no se producen de forma consecutiva, sino que se reanudan pasados días o incluso meses. Los encuentros, de los que no se especifica un escenario - aunque bien se puede entender que estarían situados en la plaza Dam, que es el corazón del ambiente de la Bolsa-, están guiados por el personaje del Accionista, que es quien adopta el papel magistral con respecto a los demás interlocutores ${ }^{35}$.

Resulta conveniente atender los papeles que asumen estos tres personajes, los cuales vienen determinados por la mímesis conversacional ya que, si el Accionista es que soporta el peso de las discusiones, cabe preguntarse a qué responden los roles del Filósofo y del Mercader. No cabe duda de que es el producto de un proceso narratológico y dialógico que le permiten a Penso ofrecer dos puntos de vista alternativos a los que propone el Accionista, los cuales conocía perfectamente el autor: la perspectiva que tenía como mercader, profesión que ejerció desde su juventud, sobre todo en su etapa livornesa; y la de filósofo, hecho que el propio autor explica por boca del Accionista cuando dice:

33. «Conque, si el moto procede del calor, ¿cómo presumís que pueda yo fatigarme en ese continuo moto e incesable desasosiego que nos habéis descrito? Aristóteles me persuade a creer que el sosiego es perfección, con que no me podéis censurar el buscar la perfección por medio del sosiego. El Cardano sutiliza ser a veces el moto causa de quietud; con que espero que el moto con que empecé a sumergirme en ese Egeo me conduzca a la quietud a vista de la zozobra, antes que pare la tormenta en naufragio» (Penso, Confusión de confusiones, ed. Smith, p. 190).

34. Ofrezco aquí la localización exacta de los fragmentos que en los que G. F. Loredano cita a Scaligero y a Cardano, de donde Penso toma el sentido y los conceptos pero no traslada los textos: Loredano, 1649, para Scaligero, véanse las pp. 131 y 190, y para Cardano, las pp. 79 y 81. Lo mismo sucede en la Seconda parte de las Bizzarrie academiche (1646), donde se ven las citas de Scaligero en las pp. 127, 188 y 189, y las de Cardano en las pp. 75 y 79 . Evidentemente, hay más ediciones, tanto anteriores como posteriores, pero me centro en estas porque, por razones cronológicas, son las que con mayor seguridad pudo estar trabajando Penso.

35. Remito directamente a Penso, Confusión de confusiones, ed. Smith, pp. 135-136, ya que la cita que ilustra esta argumentación es realmente larga. 
El tercer inconveniente de parecer incompatible ser filósofo y accionista no debe afligiros, porque sus ruedas son como los templos egipcios, donde asistía todo género de sabandija y, aunque en el de Hércules no entraba mosca, aquí hay infinitos Domicianos que para cogerla blasonan de ser Alcides, y pocos tahúres que para pescarla dejen de ser arañas en el veneno que arrojan y delgado que hilan. También fui yo estudiante con amagos de retórico y asomo de predicador, y no faltaban amigos que al leer los panegíricos con que aplaudí a los héroes de la Europa, me lisonjeaban con título de Orfeo, aunque hoy hay muchos que añaden Orfeo "de-lira". Persiguiome la Fortuna, picada de la constancia con que me opuse generoso a sus contrastes y luego me pronosticó el dulce epíteto de Orfeo, que había de venir a parar a este Infierno ${ }^{36}$.

Esta extrapolación que hace Penso a su obra en tres niveles diferentes le permite, a su vez, encajar de manera prodigiosa tres tipos de diálogos que se pueden definir como pedagógico o didáctico, expuestos en las ponencias magistrales que hace el Accionista; el discurso de carácter polémico, representado por las argumentaciones y contra-argumentaciones que desarrolla el filósofo; y, por último, el discurso heurístico, en el que el discreto mercader trata de buscar soluciones a los problemas que presenta la Bolsa de Acciones ${ }^{37}$.

Cabe plantearse las razones por las que Joseph Penso divide Confusión de confusiones en estos tres tipos de diálogos y, para ello, es necesario que me demore mínimamente a explicar por qué está tan familiarizado con ellos. De este modo, se entenderá por qué hace uso de ellos y en base a qué criterios. A lo primero que hay que atender es al currículo de estudios de las Yeshivot que se crearon en la capital holandesa. En estas escuelas, los alumnos estudiaban retórica, además de otras disciplinas complementarias - y no como artes independientes - tales como gramática y dialéctica, sin olvidar la formación propiamente religiosa ${ }^{38}$. Los alumnos, entre los que obviamente cuento a Joseph Penso, tenían que hacer ejercicios prácticos con los que demostrar sus conocimientos en el Ars bene dicendi, escribiendo breves ejercicios retóricos sobre un tema previamente propuesto por el maestro. En estos trabajos debían redactar una interpretación exegética de la Parashá que posteriormente presentaban el Sabbath, entre las oraciones de Minah y Ma'arivi3. Estas exposiciones se pueden dividir en dos grandes grupos según su contenido

36. Penso, Confusión de confusiones, ed. Smith, pp. 13-14.

37. Esto se encuentra también explicado en Penso, Confusión de confusiones, ed. Gasós y González, pp. 151-153.

38. El maestro veneciano León de Módena explicaba que, entre sus aprendizajes, estaba también la práctica sermonaria: «l studied with Rabbi Hezekiah Finzi for eight months. It was his practice to have students studying Alfasi compose an original sermon on the lesson each Sabbath. On the Sabbath day, a minyan [ten males older than thirteenth] would be gathered in the schoolhouse, and a youngster would preach before them. When it was my turn, the lesson was Temurah (Exod. 25:1-27:19). I took as a nosé Gold and silver and bronze (Exod. 25:3), as a ma'amar, «Rabbin Simeon ben Gamaliel said, The world stand on three things, on Torah, on worship, and on deeds of loveingkindness», en Saperstein, 1989, pp. 405-406.

39. «Unmarried men under the age of twenty-five were not entitled to preach during the morning service; if their teacher permitted they could deliver a sermon in the afternnon. The parnassim and Aguilar were therefore able to dedicate this period to students of Ets Haim. Evidently private individuals had less op- 
y su intención: por un lado, aquellas que estaban destinadas al estudio en profundidad de la retórica y de la Torah, que consistían en la interpretación y comentario de pasajes de la Sagrada Escritura, y partir de ellos, los discípulos realizaban una explicación homilética de un verso bíblico. Por otro lado, hay otro tipo de discursos, conocidos como Derush, que pueden ser un debate, un vituperio o una loa en torno a un versículo correspondiente a la lectura semanal, con el objetivo de presentar ante un auditorio sus reflexiones temático-morales ${ }^{40}$.

Además de estos ejercicios, cada semana debían escribir un discurso basado en un problema o un enigma propuesto por el maestro, un thema. Por lo general, era una exégesis de un versículo de la Torah o una disyuntiva de carácter moral que discutían en grupo, tal y como se hacía en las Scholae Latinitae con lo que se conocía como declamatio o, ya en la Edad Media, como Disputatio ${ }^{41}$. Los estudiantes escribían discursos de género deliberativo, apoyando sus argumentaciones en los textos sagrados, condicionados por un papel dialógico previamente determinado, y repartidos entre suasoriae, que debían convencer con sus argumentos a los oyentes, y los controversiae, los cuales debían defender sus hipótesis antes las postulaciones de sus compañeros ${ }^{42}$. Hay que tener en cuenta que, además, estos últimos ejercicios serían la base de las principales actividades entre ingenios en las academias literarias de los Sitibundos y los Floridos ${ }^{43}$.

portunity to join these cycles of sermons, but the parnassim managed to ensure the level as well as the orthodoxy of the sermons», en Berger, 1996, p. 196.

40. Boer, 1995, pp. 214-215.

41. Berger, 1996, pp. 106-107.

42. Esta idea de confrontar los argumentos diferenciando entre los que aconsejan y los que crean controversia parece estar tomado de la Retórica de Aristóteles: «Each of the three kinds has a different special end, and as there are three kinds of Rhetoric, so there are three special ends. The end of the deliberative speaker Is the expedient or harmful; for he who exhorts recommends a course of action as better, and he who dissuades advises against it as worse; all other considerations, such as justice and injustice, honor and disgrace, are included as accessory in reference to this. The end of the forensic speaker is the just or the unjust; in this case also all other considerations are included as accessory. The end of those who praise or blame is the honorable and disgraceful; and they also refer all other considerations to these», en Aristóteles, Rhet. 1.3.5. En relación a las causas del género deliberativo, Cicerón explica en sus Partitiones oratoriae: Itaque cum constet hoc genus causarum ex suasione et dissuasione, suasori proponitur simplex ratio, si et utile est et fieri potest, fiat, dissuasori duplex, una, si non utile est, ne fiat, altera, si fieri non potest, ne suscipiatur. Sic suasori utrumque docendum est, dissuasori alterum infirmare sat est. Quare quoniam in his versatur omne consilium duobus, de utilitate ante dicamus, quae in discernendis bonis malisque versatur. Bonorum autem partim necessaria sunt, ut vita, pudicitia, libertas, partim non necessaria, ut liberi, coniuges, germani, parentes: quorum alia sunt per se expetenda, ut ea quae sita sunt in officiis atque virtutibus, alia quod aliquid commodi efficiunt, ut opes et copiae» (vv. 8587). Por lo tanto, es muy probable que los discursos deliberativos de las escuelas fuesen la puesta en práctica de las lecturas de los textos retóricos clásicos.

43. Sobre la reconstrucción de las academias literarias sefardíes y el papel que desarrolló Joseph Penso en cada una de ellas, remito a Pancorbo, 2018, pp. 92-131. En estas páginas, además de encontrar un detallado estado de la cuestión sobre la historia de los Sitibundos y los Floridos, ofrezco documentación nueva sobre estas congregaciones literarias. 
Teniendo en cuenta este apunte, se puede ver que las aportaciones del Accionista son parlamentos de carácter demostrativo con los que, además de ofrecer una lección casi enciclopédica sobre la Bolsa, pone sobre aviso a sus compañeros de tertulia de los engaños e irracionalidades que impiden llegar a una conclusión y una verdad universal sobre este asunto. La presencia del Filósofo favorece la creación de un discurso deliberativo, heredero de esa disputatio medieval anteriormente señalada, en el que los papeles se encuentran establecidos desde el comienzo de la obra: el Accionista debe demostrar la veracidad de lo que expone -es decir, le toca la función suasoria-; mientras que el Filósofo y el Mercader aportan a la conversación planteamientos y argumentaciones que no son necesariamente contrarias, pero que intentan hacer prevalecer por encima de las explicaciones del Accionista, o sea, en este caso, ambos adquieren una función de controversiae. Y, finalmente, el diálogo heurístico, entendiéndolo como un diálogo cooperativo en busca del conocimiento y de la verdad, a imagen y semejanza de aquellos que tenían lugar entre los sitibundos y los floridos.

No obstante, parece que remontarse hasta su época estudiantil para dar explicación al origen de estos diálogos, o fijarse solo en esta explicación, sería remoto y se dejaría de tener en cuenta que Penso, así como la mayoría de autores de su entorno, siempre trataban de imitar -o incluso de superar- a algún modelo que, además, sería el que le ofreciese el marco teórico y poético de sus obras. En este sentido, es sencillo ver que, si se está hablando de un conjunto de discursos de tipo académico, su principal ejemplo a seguir fuese Giovan Francesco Loredano. Esto se explica fundamentalmente por dos razones. La primera, porque las obras que escribe el veneciano en para los círculos académicos -me refiero a todos sus discursos, bizarrías y ejercicios - estaban basados en intereses políticos de la república y en las inquietudes de los ciudadanos, semejante tono de preocupación que se advierte en el prólogo de Confusión de confusiones ${ }^{44}$. La segunda razón me lleva a hablar del aspecto teórico que toma de manera de las Bizzarrie academiche y de los Discorsi politici e morali sopra Salustio, de Loredano. A lo largo de la primera obra se pueden ver escritos diálogos didácticos y heurísticos, propios de las sesiones en las que participaba con sus compañeros de palestra en la Accademia degli Incogniti -institución que tomaría Penso como base para crear la de los Sitibundos en Livorno en la década de $1670^{45}$ - . Lo mismo sucede con algunos ejemplos polémicos en torno a cuestiones filosóficas como «Perché Pitagora prohibi l'uso delle Fave» 0 «Se l'arrosire sia inditio di virtù» ${ }^{46}$.

44. Los discursos académicos que se escribieron en el entorno de los Incogniti presentan un claro compromiso social y político relacionado con el contexto Renacentista italiano, algo que heredaron las academias sefardíes, por intermediación de Penso, y que se encuentra estudiado en Miato, 1998, pp. 71-72. 45. En cuanto a la configuración de esta academia veneciana, creo muy interesante el trabajo de Lattarico, 2012.

46. Ofrezco algunos títulos de discursos didácticos, como «l pregiudizi della bella Creanza» (pp. 3536), o «Gli amori sacrileghi» (pp. 37-46); así como de aquellos que son heurísticos, como «Perché i Medici procurano haver la Barba grande» (pp. 50-56), o «Se la lontananza sia il vero rimedio d'Amore. Introduzione al problema» (pp. 78-80). Cito por la edición de las Bizzarrie accademiche, de 1649. 
Es necesario advertir que los interlocutores, a lo largo de los cuatro diálogos, no presentan en sus parlamentos un nivel retórico tan agudo como el que exhibirían los académicos en las palestras literarias. De hecho, hay un pasaje en el segundo diálogo que, además de evidenciar este hecho, va a dar la clave para entender cuál va a ser el estilo de la obra y, más concretamente, el de los dialogantes:

Mercader Dos dificultades encuentro en ese anhelo y me obliga el amor a especificarlas, aunque presumáis que las presento más como envidioso que como amigo. La primera, tener algo de picante todo lo que nos habéis comunicado y ser muy cierto que tiene la mordacidad sus paralelos con la justicia, pues todos la procuran en su país, ninguno en su casa. Halaga a quien la oye, ofende a quien la teme, y siempre son muchos más los que la recelan que los que la aplauden. La segunda, ser el estilo con que nos habéis descrito este enredo muy realzado para el pueblo, muy noticioso para el vulgo y muy abominable para los que, topando con alguna erudición en que se alega con algún filósofo, con algún matemático o con algún astrónomo, maldicen (como ya ha sucedido) tantos reyes, pareciéndoles que hasta los sastres con que se apoyan los conceptos son monarcas y que hasta los boticarios con se ilustran son las pruebas de los emperadores [...].

Accionista Satisfaré esos escrúpulos y solicitaré que reconozcáis por el efecto que no os deshago esas nubes como a envidiosos, sino como amigos. Que el estilo sea algo remontado, confieso y determino disculparme en el prólogo, ya que debiendo traer lo que vos me contradecís y lo que yo os respondo. Si nuestro filósofo no quiso despegarse de sus doctrinas filosóficas, dogmas metafísicos y galanterías dialécticas, no es razón que yo le cercene al diálogo este ornato, y que le usurpe a la obra esta corona ${ }^{47}$.

La cuestión es que, aunque realmente Penso evita explayar todo su repertorio de florituras retóricas y de sus juegos conceptuales ${ }^{48}$, Confusión de confusiones acaba por ser un texto que, muy posiblemente, no estuviese al alcance cultural de todos los lectores, ya que el respeto que le confiere al decorum, así como la complejidad y el desconocimiento de la temática hacen que la obra tenga una dificultad muy alta. Por ello, a modo de excusatio, dice el autor que:

Si hubiere algún período que no sea inteligible a los que no han estudiado filosofía, dialéctica o metafísica, sirva de disculpa al realce ser justo que hable el filósofo como filósofo, el mercader como mercader y el accionista como accionista, uno de sus libros, otro de sus negocios, y el último de sus agudezas, aunque discurriendo el segundo como discreto y el tercero como erudito, no será mucho que a veces sublimen el estilo y remonten el vuelo. La intención ha sido de aprovechar. Quiera Dios que consiga el premio de merecer ${ }^{49}$.

47. Penso, Confusión de confusiones, ed. Smith, pp. 64-65.

48. Sobre el conceptismo en Penso de Vega, ya hay una publicación realizada por Rebollo Lieberman, 2000. No obstante, la adscripción del estilo de Penso al conceptismo, tal y como se entiende en el Barroco español, creo que no es del todo exacta, ya que habría que tener en cuenta que los aspectos retóricos de los que él era conocedor condicionaban también el uso del concepto, no como un elemento estético o poético, sino como una parte del discurso deliberativo.

49. Penso, Confusión de confusiones, ed. Smith, p. VII. 
En conclusión, el estudio de Confusión de confusiones, obra que le ha dado una merecida fama a Joseph Penso hasta nuestros días - aunque no se ha reconocido el resto de sus obras como sería necesario-, no se puede realizar buscando pistas o referentes ligados exclusivamente a los patrones marcados por la tradición literaria del Barroco español, como ha sucedido en la mayoría de los casos y con respecto a la práctica totalidad de la obra del sefardí. He aquí la explicación de que se haya estado considerando durante mucho tiempo como un experimento a caballo entre las memorias de un corredor arruinado, y un intento de tratado sobre la Bolsa de Acciones, sin hacer ajustarse ninguna de estas categorías a lo que el autor sefardí realmente ofrece. Así, elementos como su título o la descripción de los diálogos han sido un quebradero de cabeza para muchos investigadores que se han asomado a la obra sin tener una idea clara de lo que en realidad significa Confusión de confusiones. Quizás, la razón más lógica sea el no haber podido encontrar unos referentes previos sobre los que hacer un estudio a nivel teórico, estilístico e, incluso, interpretativo.

No obstante, este no es un hecho aislado, ya que ha sucedido con otras obras de Penso, como 'Asîrê ha-Tiqwâ (1670) o Rumbos peligrosos (1683). Confusión de confusiones es una miscelánea en la que confluyen de manera prodigiosa en un solo volumen los tres géneros discursivos, con los que él estuvo familiarizado desde su época escolar, para presentar un tema ignorado por la mayoría de sus lectores. Por lo tanto, se puede terminar con la idea clara de que la obra más famosa de Joseph Penso es un texto meramente literario, que se apoya en diferentes tradiciones y en elementos teóricos y retóricos diferentes para poner en relación sus experiencias con una temática que, para la época y para la mayoría de la sociedad era prácticamente desconocido.

\section{BiBLIOgRAFíA}

Aristóteles, Rhetoric, trad. John H. Freese, Cambridge/London, Harvard University Press, 1926, vol. 22.

Cicerón, Marco Tulio, De Partitione oratoria, ed. Augustus S. Wilkins, Oxford, Typographeo Clarendoniano, 1991.

Boletín de La Librería, Madrid, Librería de M. Murillo, 1874.

Catalogue raisonné de la Bibliothèque d'un Chateau de Lorraine. Collection de feu M. Edouard Le Petit, de Maxéville et de livres rares et curieux manuscrits et imprimés provenant de la collection de M. W... S... de Londres, vol. I, París, A. Claudin, 1862.

Barrios, Miguel de, Dios con nosotros, Ámsterdam, [s. n.], 1688.

Berger, Shlomo, Classical Oratory and the Sephardim of Amsterdam: Rabbi Aguilar's Tratado de la retórica, Hilversum, Verloren, 1996. 
Bodian, Miriam, Hebrews of the Portuguese Nation: Conversos and Community in Early Modern Amsterdam, Bloomington (Indianápolis), Indiana University Press, 1997.

Boer, Harm den, «Ediciones falsificadas de Holanda en el siglo XVII: escritores sefarditas y censura judaica», en Homenaje a José Simón Díaz, Kassel, Reichenberger, 1987, pp. 99-104.

Boer, Harm den, La literatura sefardí de Ámsterdam, Alcalá de Henares, Instituto Internacional de Estudios Sefardíes y Andalusíes, 1995.

Boer, Harm den y Jonathan I. Israel, «William III and the Glorious Revolution in the Eyes of Amsterdam Sephardic Writers: the Reactions of Miguel de Barrios, Joseph Penso de la Vega, and Manuel de Leão», en The Anglo-Dutch Moment. Essays on the Glorious Revolution and its World Impact, ed. Jonathan I. Israel, Cambridge, Cambridge University Press, 1991, pp. 439-461.

Bregoli, Francesca, Mediterranean Enlighment: Livornese Jews, Tuscan Culture, and Eighteenth-Century Reform, Standford, Standford University Press, 2014.

Calderón de la Barca, Pedro, La dama duende, ed. Fausta Antonucci, Barcelona, Crítica, 1999.

Calderón de la Barca, Pedro, El divino cazador, ed. Ignacio Arellano y Carmen PiniIlos, Pamplona/Kassel, Universidad de Navarra/Edition Reichenberger, 2014.

Cardoso, José Luís, «Confusión de confusiones: Ethics and Options on Seventeenth-Century Stock Exchange Markets», Finanacial History Review, 9.2, 2002, pp. 109-123.

Chaeudhuri, K. N. y Jonathan I. Israel, «The English and Dutch East Companies and the Glorious Revolution of 1688-9», en The Anglo-Dutch Moment. Essays on the Glorious and its World Impact, ed. Jonathan I. Israel, Cambridge, Cambridge University Press, 1991, pp. 421-429.

Duivenvoorde, Wendy van, Dutch East India Company Shipbuilding, Texas, Texas A\&M University, 2015.

Dumez, Hervé, «The Description of the First Financial Market: Looking Back on Confusión de confusiones by Joseph Penso de la Vega», en Gérer \& Comprendre, English Language Edition, 9, vol II, 2003, pp. 5-9.

Fernández Ruiz, Óscar, Las relaciones hispano-inglesas entre 1603 y 1625. Diplomacia, comercio y guerra naval, tesis doctoral, Valladolid, Universidad de VaIladolid, 2012.

Gaastra, Femme S., The Dutch East India Company: Expansion and Decline, Zutphern, Walburg Pers, 2003.

Gosselink, Martine, «The Dutch East India Company in Asia», en Asia in Amsterdam. The Culture of Luxury in the Golden Age, Yale, Yale University Press, 2015, pp. 21-31. 
Held, Paul, «The Confusion of confusions: Between Speculation and Eschatology», en Concentric Literature and Cultural Studies, 32.3, 2006, pp. 111-144.

Israel, Jonathan I., European Jewry in the Age of Mercantilism, 1550-1750, Oxford, Oxford University Press, 1985.

Isreal, Jonathan I., Dutch Primacy in World Trade, 1585-1740, Oxford, Oxford University Press, 1989

Israel, Jonathan I., «The Republic of the United Netherlands until about 1750: Demography and Economic Activity», en The History of Amsterdam, ed. J. C. H. Blom, Renate G. Fuks-Mansfeld e Ivo Schöffer, Oxford/Portland(Oregon), The Littman Library of Jewish Civilization, 2002, pp. 85-115.

Kaplan, Yosef, «Spanish Readings of Amsterdam's Seventeenth-Century Sephardim», en Jewish Books and their Readers. Aspects and Jews in Early Modern Europe, ed. Scott Mandelbrote y Joanna Weinberg, Leiden/Boston, Brill, 2016, pp. 312-341.

Kellenbenz, Hermann, Confusión de confusiones [1688]: Portions Descriptive of the Amsterdam Stock Exchange, Boston (Massachusetts), Baker Library/Harvard Graduate School of Business Administration, 1957.

Kostolany, André, Así es la Bolsa, trad. Ana María Albareda, Barcelona, Bergara, 1962.

Landwehr, John, VOC. A Bibliography of Publications relating to the Dutch East India Company, 1602-1800, Utrecht, Hes Publishers, 1991.

Lattarico, Jean-François, Venise Incognita: Essai sur l'académie libertine au XVIle siècle, París, Honoré Champion, 2012.

Loredano, Giovan Francesco, Seconda parte de las Bizzarrie academiche, Venecia, Zenero, 1646.

Loredano, Giovan Francesco, Bizzarrie academiche (Parte prima), Venecia, II Guerigli, 1649.

Mackay, Charles, Memoirs of Extraordinary Popular Desillusions and the Madness of Crowds, Londres, National Illustred Gallery, 1852.

Miato, Monica, L'Accademia degli Incogniti di Giovan Francesco Loredan. Venezia (1630-1661), Florencia, Olschki, 1998.

Pancorbo, Fernando, Joseph Penso de Vega: la clave de un proceso intercultural, tesis doctoral, Basilea, Universidad de Basilea, 2018.

Penso, Joseph, 'Asîrê ha-Tiqwâ, Ámsterdam, Joseph Athias, 1673.

Penso, Joseph, 'Asîrê ha-Tiqwâ, Livorno, Carlo Giorgi, 1770.

Penso, Joseph, Confusión de confusiones, ed. M. F. J. Smith, Den Haag, Martinus Nikhoff, 1939. 
Penso, Joseph, Confusión de confusiones, ed. Pablo Gasós y Margarita González, Madrid, Comisión Nacional del Mercado de Valores, 2015.

Penso, Joseph, Rumbos peligrosos por donde navega con título de novelas la zozobrante nave de la temeridad, temiendo los peligrosos escollos de la censura, Amberes [Ámsterdam], [Yahacob de Córdoba], 1683.

Perramón Ayza, Joaquim M., Influència de la informació econòmica en la Bolsa a "Confusión de confusiones» (Joseph Penso de la Vega, 1688), tesis doctoral, Barcelona, Universitat Autònoma de Barcelona, 2011.

Rebollo Lieberman, Julia, «Estética conceptista y ética mercantilista de Confusión de confusiones (Ámsterdam, 1688)», Bulletin of Hispanic Studies, 77.5, 2000, pp. 407-421.

Toaff, Renzo, La nazione ebrea a Livorno e a Pisa (1591-1700), Florencia, Olschki, 1990.

Torrente Fortuño, José Antonio, La Bolsa en José de la Vega, Madrid, Ilustre Colegio de Agentes de Cambio y Bolsa de Madrid, 1980.

Trivellato, Francesca, The Familiarity of Strangers. The Sephardic Diaspora, Livorno, and Cross-Cultural Trade in the Early Modern Period, New Haven/Londres, Yale University Press, 2009.

Salvá, Vicente, A Catalogue of Spanish and Portuguese Books with Occasional Literary and Bibliographical Remark, Londres, M. Calero, 1826.

Saperstein, Marc, Jewish Preaching 1200-1800. An Anthology, New Haven/London, Yale University Press, 1989.

Vega, Félix Lope de, La Dorotea, ed. Edwin S. Morby, Madrid Castalia, 1998.

Winius, George D. y Marcus P. M. Vink, The Merchant-Warrior Pacified. The VOC (The Dutch East India Company) and its Changing Political Economy in India, Oxford, Oxford University Press, 1991. 